\title{
A 5 year track record on a galvanic CP system applied on a light weight concrete bridge with prestressed steel - Developments in time of the effectiveness as determined by depolarisation values and current densities
}

\author{
A.J. (Hans) van den Hondel $^{1 *}$, Joost Gulikers ${ }^{2}$, Roberto Giorgini ${ }^{3}$, Anthony (W.M.) van den Hondel ${ }^{4}$ \\ ${ }^{1}$ Vogel Cathodic Protection, Zwijndrecht, The Netherlands \\ ${ }^{2}$ Rijkswaterstaat-GPO, Utrecht, The Netherlands \\ ${ }^{3}$ CorrPRE, Moordrecht, The Netherlands \\ ${ }^{4}$ Cathodic Protection Advice, Capelle aan den IJssel, The Netherlands
}

\begin{abstract}
This paper gives insight in the research and investigations which were undertaken on a post tensioned light-weight concrete box girder bridge in the Netherlands. This project started in the first half of 2013 and measurements are still executed regularly. Due to long-term leakage of a longitudinal joint between 2 parts of the bridge, chlorides had penetrated into the concrete up to the level of the reinforcement and beyond, causing severe corrosion of the steel, spalling of the concrete cover and eventually causing danger for the shipping underneath the bridge due to falling lumps of concrete. To solve this problem, Galvanic Cathodic Protection (GCP) was applied in 2 stages. Firstly, in 2013, zinc based anode strips were applied on the soffit of 2 post tensioned lightweight bridge segments for the purpose of testing and monitoring. After obtaining good results from the test, in 2014/2015 the remaining 29 bridge segments were repaired and protected with the same GCP system as well. This paper reviews subsequent potential decay and current densities measurements, which have provided valuable information on GCP performance and throwing power. The results of anode performance at different locations and depths are reviewed. Concrete resistivity have shown a major influence on the effectiveness of the installed GCP system.
\end{abstract}

\section{Introduction}

\subsection{The object}

The object concerns the Neerbossche Bridge which spans a canal at Nijmegen, The Netherlands (Figure 1).

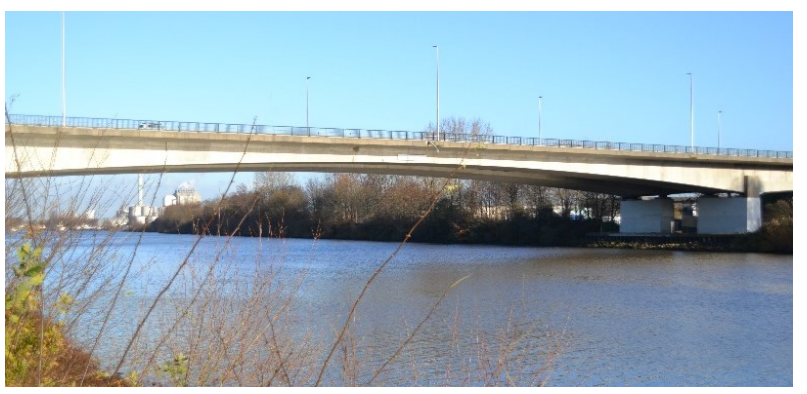

Fig. 1. The Neerbossche Bridge over the Maas-Waal canal.

The bridge is a post tensioned double box girder bridge from 1982, of which the structure above the canal is constructed with light-weight concrete $\left(1650 \mathrm{~kg} / \mathrm{m}^{3}\right)$. The in-situ cast concrete segments have a length of about 3.4 meters. For each box girder, the part of the bridge located between the piers comprises 33 segments of which the 2 segments above the piers are constructed with conventional normal weight concrete. So each box girder is comprised of 31 light-weight concrete segments above the canal. The soffit of the light-weight concrete sections of the southern box girder showed serious damage and consequently maintenance was required in the short term in view of structural safety as well as possible danger for the shipping underneath the bridge due to falling lumps of concrete.

\subsection{The project}

The damage in the bridge was extensively investigated and reported ([1]) in a preliminary phase and it was concluded that the damage was limited to the concrete surface at the soffit of the northern cantilever of the span of the southern bridge (see Figure 2). Due to long-term leakage in the longitudinal joint between the northern and southern bridge, chlorides originating from the frequent application of de-icing salt during winter periods had penetrated into the concrete up to the level of the reinforcement and beyond. As a consequence, the mild steel reinforcement had started to corrode which even-

* Corresponding author: hansvandenhondel@icloud.com \& hvdhondel@mourik.com 
tually resulted in the development of significant tensile stresses in the concrete, leading to cracks, delamination's and spalling at multiple locations.

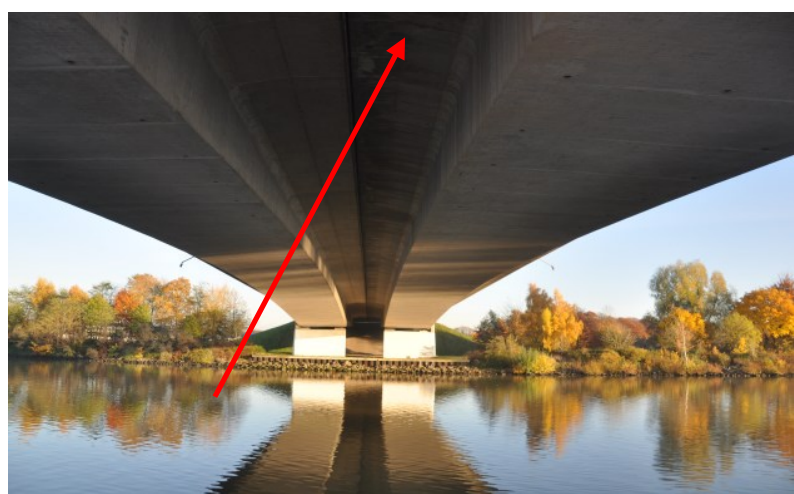

Fig. 2. Location of the damaged cantilever (southern bridge).

The corrosion induced damage amounted to approximately $44 \mathrm{~m}^{2}$, which was about $22 \%$ of the total surface of the soffit. At other locations, the likelihood of corrosion was demonstrated by corrosion potential measurements which showed values down to $-450 \mathrm{mV}$ $\left(\mathrm{Cu} / \mathrm{CuSO}_{4}\right)$ and $-350 \mathrm{mV}(\mathrm{Ag} / \mathrm{AgCl}$; see Figure 3$)$.

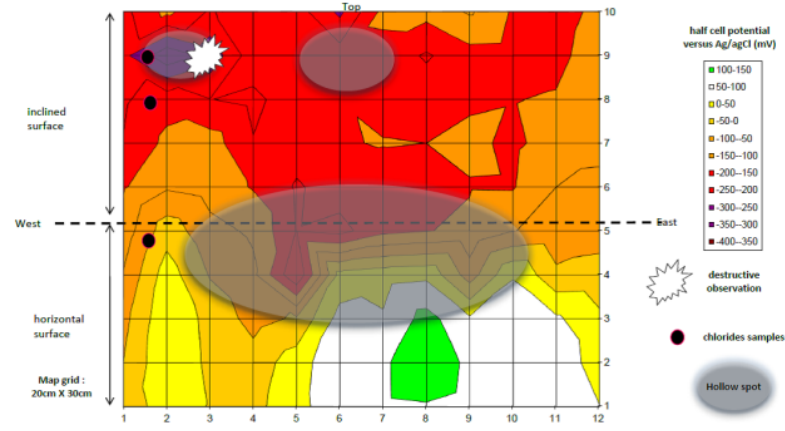

Fig. 3. Corrosion potential measurements at the cantilever in the southern bridge. The grey areas denote hollow spots and the white flash a destructive investigation point.

As a long-term solution to this problem, cathodic protection (CP) was considered to present a viable and economical option. As the structure was post tensioned, Galvanic Cathodic Protection (GCP) was in favor to be applied in order to avoid the risk of hydrogen embrittlement in the high quality steel tendons. In the summer of 2013 the steel reinforcement in 2 bridge segments was protected with zinc based strip anodes, for testing purposes applied in small size foils which could be connected to the reinforcing steel on and off separately. Also a large number of reference electrodes (titanium decay probes, referred to as RE's) were embedded in the concrete of these 2 segments in order to monitor the effectiveness of the CP system, not only within the protected area but also outside the protected area.

With these 'remote' RE's the so-called throwing power of this CP system could be established. For the same reason RE's were installed at different depths in the concrete cover as well as in repaired areas in order to study the corrosion behavior of the steel in these areas due to the action of the CP system.
In view of the good results that were obtained in this test and the suitability of this GCP system was proven, the full scale project on the remaining 29 bridge segments was executed in the winter of 2014/2015.

\subsection{The application of the GCP system}

The highlights of the full scale project in 2014/2015 were reported extensively in 2016 ([2]), with respect to the accessibility of the soffits 10 meters above the water level, the application of shotcrete using a light-weight mortar with a high cement content and no additives for the concrete repairs and the application of the GCP system (Figure 4-6).

The anode material used for the protection of the steel reinforcement was a surface mounted zinc anode. This so called Zinc Layer Anode (ZLA) is applied as a foil on the surface and consists of a $250 \mu \mathrm{m}$ thick zinc sheet provided with a $750 \mu \mathrm{m}$ thick ion-conductive adhesive.

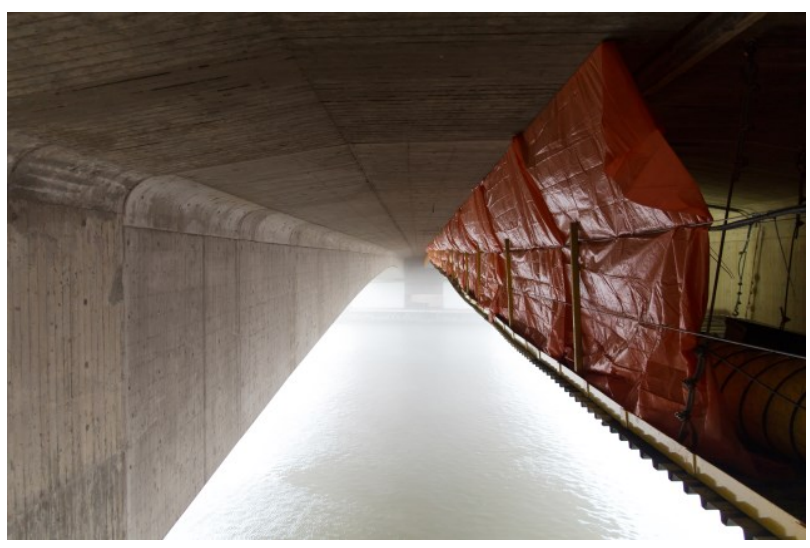

Fig. 4. Access to the soffit at the damaged cantilever.

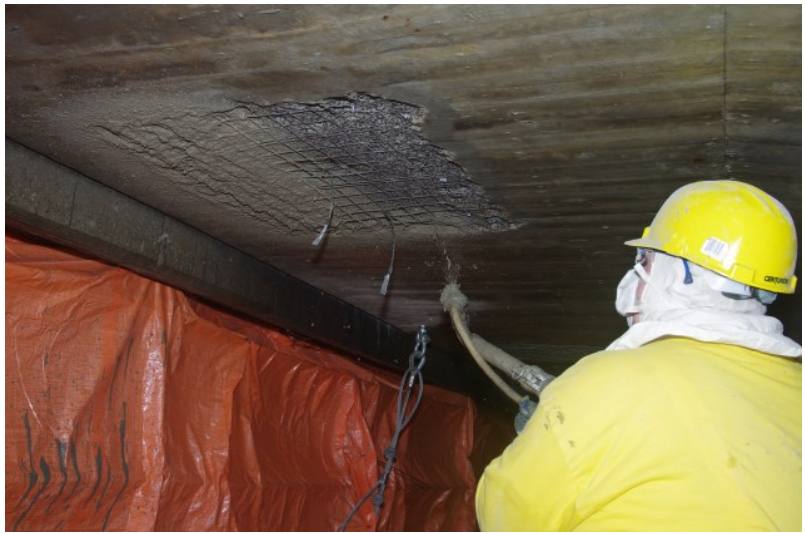

Fig. 5. Repair of the damaged locations with shotcrete.

The complete zinc surface, including the edges, was covered with a $2 \mathrm{~mm}$ waterproof cement based coating in order to prevent the zinc from direct contact with moisture due to condensation and the resulting atmospheric corrosion. 


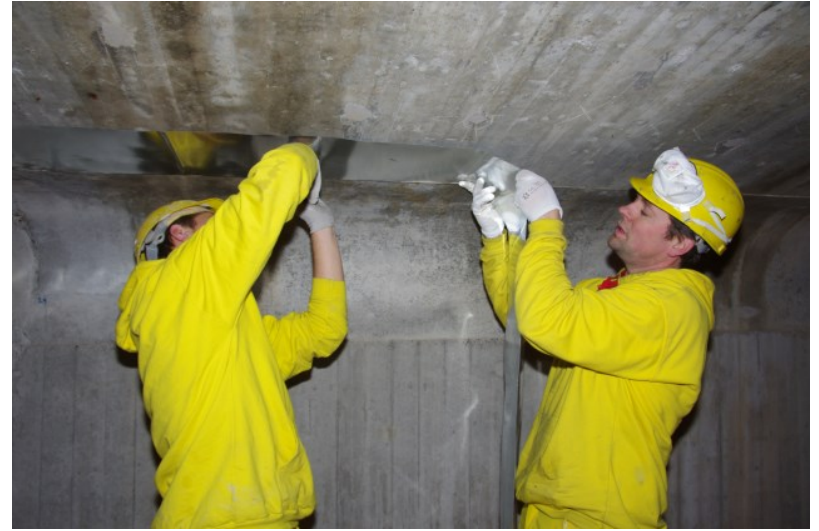

Fig. 6. Application of the zinc anode in $25 \mathrm{~cm}$ strips.

\subsection{Scope of the paper}

This paper will focus on the new data and insights from the still ongoing research and investigation on the effecttiveness of the GCP system over time, by measuring potential decay values and current densities.

\section{Developments in time of the effective- ness of the GCP system}

\subsection{The test segments}

The original test provisions from 2013 on the 2 segments (see Figure 7; [2]), with a large amount of RE's and the narrow zinc strips (with a width of $83 \mathrm{~mm}$ ), were kept unchanged, as much as possible, during the full scale project in $2014 / 2015$ in order to be able to continue the monitoring of the GCP system and to start research of the long-term effects of this type of GCP systems with a surface mounted anode.

Since 2013 depolarisation measurements of the CP system in different seasons have been carried out, using all the RE's in and remote from the protected area, as well as in depth. The amount of protection current being generated by each zinc strip was measured and monitored in order to predict the service life of the (sacrificial) anodes. Also other system parameters, such as the resistance in all the components, were monitored. These measurements were carried out during almost 5 years and show interesting results, expanding the knowledge on GCP and the long-term effects on potential decay values, (protective) current densities and the throwing power of galvanic anodes, as well as the influence of repair mortars and the moisture content of the concrete on the behavior of installed GCP systems.

\subsection{Data and properties of the test segments}

Two bridge segments (of 33) were selected in 2013:

1 . Segment 2 with $4 \%$ of concrete damage, a concrete cover between $29 \mathrm{~mm}$ and $45 \mathrm{~mm}(\mu=37 \mathrm{~mm})$ and corrosion potential measurements with values from $0 \mathrm{mV}$ down to $-270 \mathrm{mV}\left(\mathrm{Cu} / \mathrm{CuSO}_{4}\right)$
2 . Segment 3 with $33 \%$ of concrete damage, a concrete cover between $25 \mathrm{~mm}$ and $46 \mathrm{~mm}(\mu=38 \mathrm{~mm})$ and corrosion potential measurements with values from $-30 \mathrm{mV}$ to $-350 \mathrm{mV}$ (at the location of the damage)

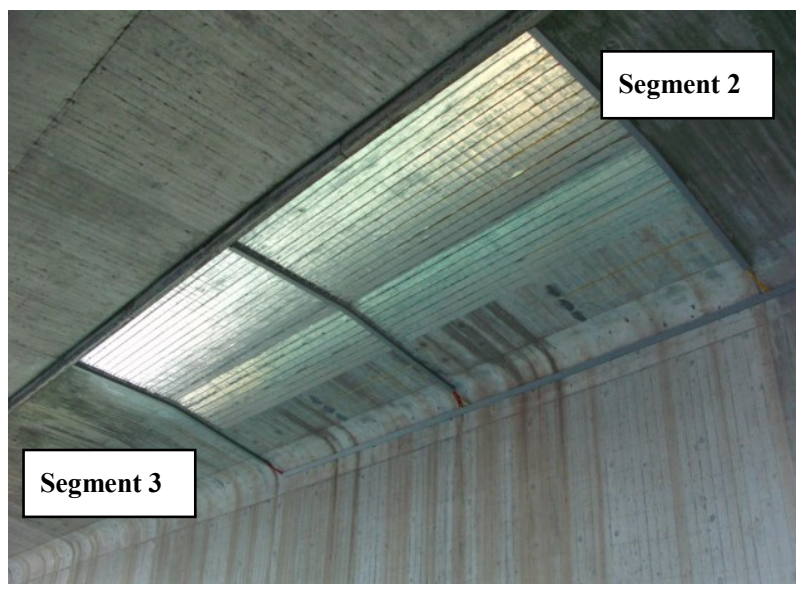

Fig. 7. Test locations with the zinc anode material.

The reinforcement of the soffit was placed in 2 layers, crosswise, with rebar's of Ø12 mm and Ø16 mm in diameter. The carbonation depth as measured in the soffit varied between $2 \mathrm{~mm}$ to $11 \mathrm{~mm}$, however high chloride contents were measured, up to $3 \%$ on cement weight and up to depths of over $50 \mathrm{~mm}$.

The CP system at the test segments was applied on the horizontal part of the cantilever and the adjacent 50 $\mathrm{cm}$ of the inclined segment (thus over a total width of 2 meters). Each test segment was in this way covered with $6.2 \mathrm{~m}^{2}$ of ZLA (see Figure 7).

\subsection{Effectiveness of the installed GCP system}

The measurements were carried out using the titanium decay probes (RE's), embedded in the concrete of the first 2 segments, in and remote from the protected area.

From the start in 2013 measurements showed that the applied GCP system was effective. The depolarisation (potential decay) values of the $1^{\text {st }}$ layer of reinforcement mostly met the code based CP criteria (ISO-EN 12696; [3]), i.e. a minimum of $100 \mathrm{mV}$ depolarisation after 24 hours or $150 \mathrm{mV}$ after complete depolarisation (see Figure $8 \& 9$ ). The potential decay values of the $1^{\text {st }}$ layer decreased in time: with $48 \%$ in 4 years at segment 2 and with $17 \%$ in the first year and $63 \%$ in the next 3 years after replacement of the anode material at segment 3 .

Furthermore it was found, from the RE's placed at different depths in the concrete cover, that in segment 2 the $2^{\text {nd }}$ layer of reinforcement is protected as well. However, in segment 3 the results are far less positive and the potential decay values decreased rapidly in time after the replacement of the anode material in 2014/2015 (with $76 \%$ in 3 years, to an average ( 24 hours) value of 64 $\mathrm{mV}$ ). The code based CP criteria are no longer met at all 4 RE's, although it should be noted that 2 of the RE's are placed in repaired locations (RE7 \& RE8). The same is applicable to the remaining 2 RE's placed at the $1^{\text {st }}$ layer of reinforcement in repaired areas of segment 3 (RE9 \& RE10). From the start they showed less depolarisation 
than similar RE's in non-repaired locations and in 2017 the code based criteria are not met.

In general, the potential decay values of the $2^{\text {nd }}$ layer were less compared to the ones located in the $1^{\text {st }}$ layer of reinforcement. As an average, during 4 years 64\% to $94 \%$ of the potential decay values of the $1^{\text {st }}$ layer were measured at the $2^{\text {nd }}$ layer of reinforcement in segment 2 and $57 \%$ to $97 \%$ in segment 3 . It should be noted that the $2^{\text {nd }}$ layer showed less concrete damage compared to the $1^{\text {st }}$ layer and levels of chloride contamination were lower.

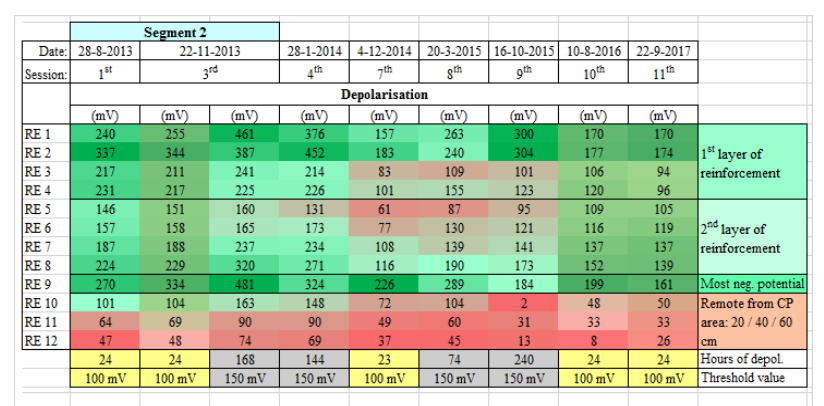

Fig. 8. Depolarisation values of segment 2.

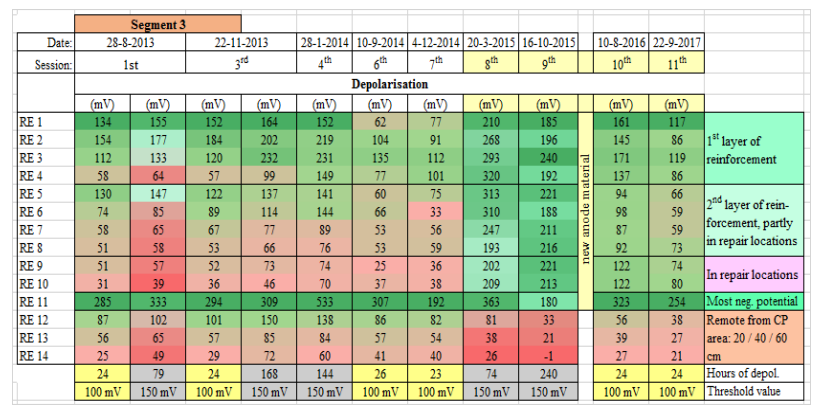

Fig. 9. Depolarisation values of segment 3 .

The best results in segment 3 were clearly obtained for the reinforcement showing the most negative natural potentials prior to installation of the CP system (RE11). In segment 2 , the potential decay values of the similar reference electrode (RE9) were also more than satisfactory with a 4 years average of $251 \mathrm{mV}$ (after 24 hours of depolarisation).

Finally, the measurements also showed that the CP system was not only effective in the protected area but also at a limited distance from the protected area. At the start in 2013 and during the first year after installation, the measurements showed that the code based criteria were met at least up to $20 \mathrm{~cm}$ adjacent to the protected area. In time the potential decay values in this area decreased considerably and since December 2014 the code based criteria are no longer met at $20 \mathrm{~cm}$ from the anode material.

\subsection{Development in time of potential decay values}

The measured values of the depolarisation in the protected area decreased over time (Figures 10 and 11). At the start in 2013 the measurements showed higher values indicating that the applied GCP system complied with the code based ISO-EN12696 criteria ([3]) at almost all locations where RE's are installed, resulting in sufficient protection of the reinforcement.

After 17 months (in December 2014) 4 out of 5 RE's $(80 \%)$ at the $1^{\text {st }}$ layer of reinforcement in segment 2 still met the code based protection criteria (compared to $100 \%$ compliance in 2013). In October 2015, more than 2 years after the installation of the GCP system, this is reduced to 3 out of 5 RE's $(60 \%)$ at the $1^{\text {st }}$ layer. Since then the results at different measuring moments (in 2016 and 2017) are stabilized and $60 \%$ to $100 \%$ of the RE's still meet the protection criteria.

The RE's placed at the $2^{\text {nd }}$ layer of reinforcement in segment 2 behave more or less in the same way. After 17 months 2 out of 4 RE's $(50 \%)$ still met the code based protection criteria (compared to $100 \%$ compliance in 2013). In October 2015 this is further reduced to $25 \%$, but since then the measurement results are back to $100 \%$ compliance.

In segment 3 the reaction of the RE's is less favorable. Starting with a compliance of $80 \%$ in 2013, after 17 months this is reduced to $60 \%$ ( 3 out of 5 RE's) at the $1^{\text {st }}$ layer of reinforcement. At the $2^{\text {nd }}$ layer of reinforcement in segment 3 only $1 \mathrm{RE}(25 \%)$ met the code based protection criteria at the start in 2013 . After 17 months these criteria are no longer met at any of these RE's ( $0 \%)$.

At segment 3 a part of the zinc anode, as well as the majority of the RE's, were replaced during the full scale project in 2014/2015 due partly to repair mortar disbondment in the test phase (not corrosion related). As a consequence, the last measurements with the original anode material dated from December 2014. After repairing the disbonded areas with shotcrete and replacing parts of the zinc anode the system reacted immediately and showed good results again. In march 2015 the GCP system (with partly new zinc anode material) met the code based criteria again, indicating sufficient protection of the reinforcement at all locations where RE's are installed, i.e. at both the $1^{\text {st }}$ and $2^{\text {nd }}$ reinforcement layer and in the repaired areas. Moisturizing of the concrete and the new installed anode material can be the explanation for this observation.

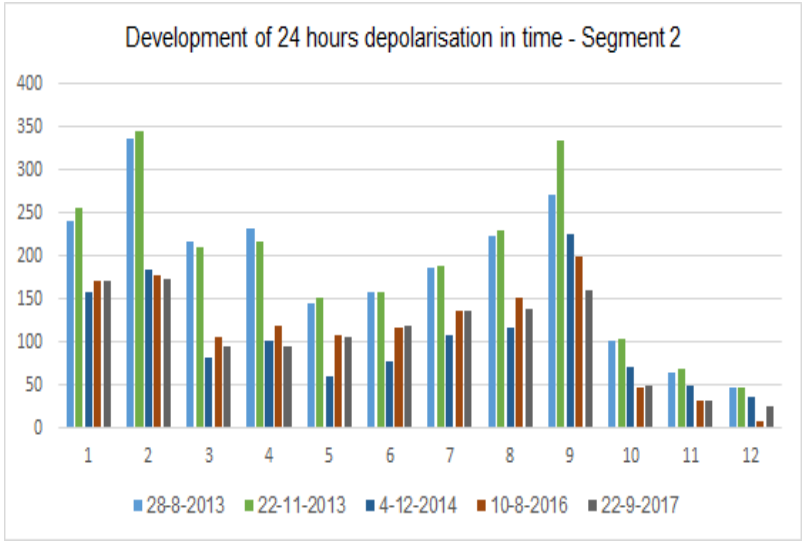

Fig. 10. 24 hours depolarisation values of segment 2 . 


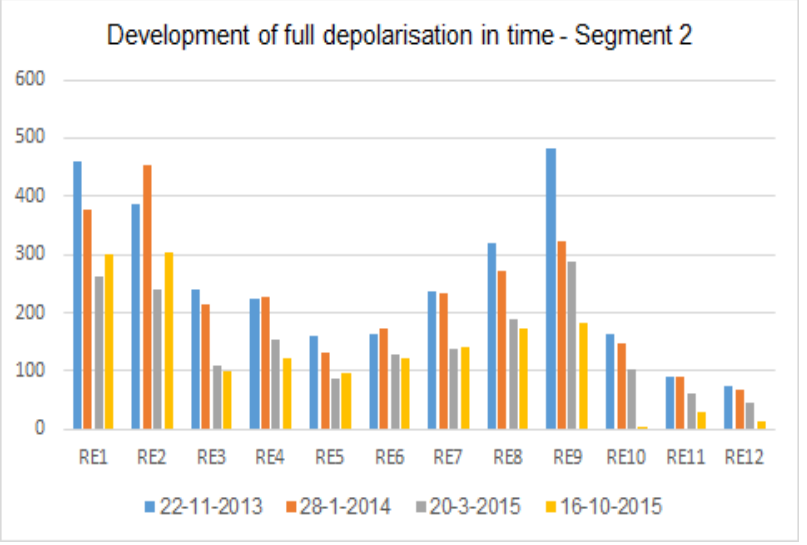

Fig. 11. Full depolarisation values of segment 2.

In August 2016 all 7 RE's (100\%) at the $1^{\text {st }}$ layer of reinforcement in segment 3 still met the code based protection criteria, including the RE's in the repaired areas. In September 2017 this was reduced to $43 \%$ (3 out of 7 RE's). At the $2^{\text {nd }}$ layer of reinforcement none of the RE's $(0 \%)$ is in 2016 still in compliance with the criteria and in 2017 the potential decay values are further reduced. Drying out of the concrete and polarisation of the steel are considered to be the explanation for this observation.

The best result in segment 3 is in 2017 still coming from the reinforcement with the most negative natural potentials prior to $\mathrm{CP}$ installation (RE11).

At the areas located more remote from the anode, i.e. adjacent to the protected surface, similar observations were found. At the start in 2013 and during the first year after installation the protected area stretched out at least up to $20 \mathrm{~cm}$ adjacent to the anode material, meeting the code based criteria. In time the potential decay values of the RE's at $20 \mathrm{~cm}, 40 \mathrm{~cm}$ and $60 \mathrm{~cm}$ decreased with approximately 50\% and in 2017 the code based criteria are no longer met at any of these RE's. The positive side effect due to the so called 'throwing power' was no longer measured after 2 years, not even at a distance of 20 $\mathrm{cm}$ from the anode material. Drying out of the concrete is considered to be the explanation for this observation.

Finally, the RE's placed in repaired areas (segment 3; RE 7-10) showed, after having disbonded areas from the test phase repaired and zinc anodes replaced (December 2014), sufficient depolarisation at all locations. The most probable explanation for the negative outcome of the potential decay values at these RE's during the first 17 months lies in disbondment of the repair mortar. Almost 3 years after the replacement, in September 2017, none of the RE's $(0 \%)$ placed in repaired areas is still in compliance with the criteria. Drying out of the concrete and polarisation of the steel are considered to be the explanation for this observation.

\subsection{Development in time of the current density}

The current output readings were carried out for each separate zinc foil (22 strips per segment with a width of $83 \mathrm{~mm}$ and a total zinc surface of $0.28 \mathrm{~m}^{2}$ for each strip) at 5 moments in time. The total current output was meas- ured as well for the complete anode system per segment (with a total zinc surface of $6.2 \mathrm{~m}^{2}$ ).

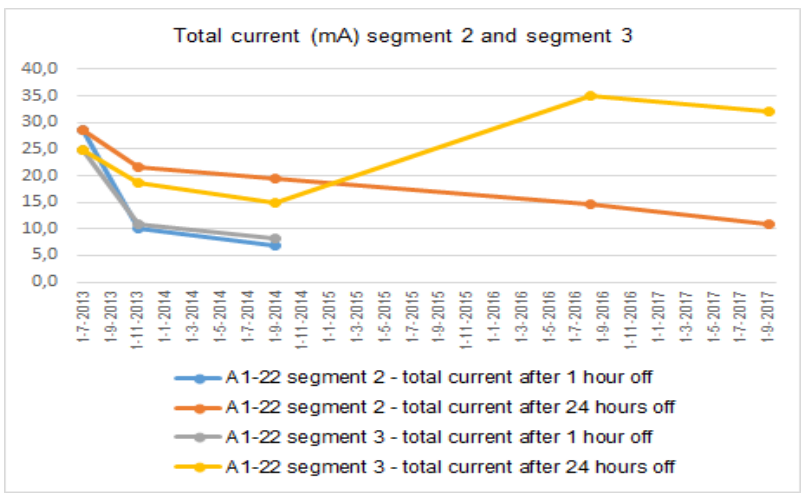

Fig. 12. Development of the total current output in time for segments 2 and 3.

The measured current outputs decreased over time (see Figures 12-14), with a strong accent in the first months. At the start in 2013 the total current output amounts to $28.6 \mathrm{~mA}$ (equal to $4.6 \mathrm{~mA} / \mathrm{m}^{2}$ anode and roughly $7.7 \mathrm{~mA} / \mathrm{m}^{2}$ steel) and $24.8 \mathrm{~mA}$ (equal to $4.0 \mathrm{~mA} / \mathrm{m}^{2}$ anode and roughly $6.7 \mathrm{~mA} / \mathrm{m}^{2}$ steel) for segment 2 and 3 , respectively. After 14 months the total current output was reduced (measured 1 hour after switching off the GCP system) to $6.8 \mathrm{~mA}$ (equal to $1.1 \mathrm{~mA} / \mathrm{m}^{2}$ anode, roughly 1.8 $\mathrm{mA} / \mathrm{m}^{2}$ steel and $76 \%$ reduction) and $8.1 \mathrm{~mA}(1.3$ $\mathrm{mA} / \mathrm{m}^{2}$ anode, roughly $2.2 \mathrm{~mA} / \mathrm{m}^{2}$ steel and $67 \%$ reduction). After 3 and 4 years the current output was measured after switching off the system for 24 hours. In segment 2 a total current output of $14.6 \mathrm{~mA}$ was measured in 2016 and $10.8 \mathrm{~mA}$ in 2017 (equal to 2.4 and $1.7 \mathrm{~mA} / \mathrm{m}^{2}$ anode respectively and roughly 4 and $2.8 \mathrm{~mA} / \mathrm{m}^{2}$ steel; a reduction of $26 \%$ in 1 year).

After replacement of parts of the zinc anode in segment 3 in December 2014, the current output increased. After switching off the system for 24 hours $35 \mathrm{~mA}$ was measured in 2016 and $32 \mathrm{~mA}$ in 2017 (equal to 5.7 and $5.2 \mathrm{~mA} / \mathrm{m}^{2}$ anode respectively and roughly 9.4 and 8.6 $\mathrm{mA} / \mathrm{m}^{2}$ steel; a reduction of only $9 \%$ in 1 year).

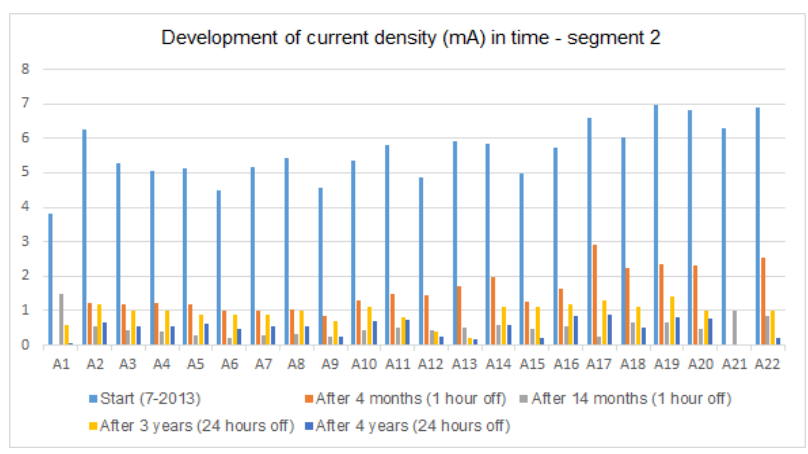

Fig. 13. Development of current output in time for segment 2. 


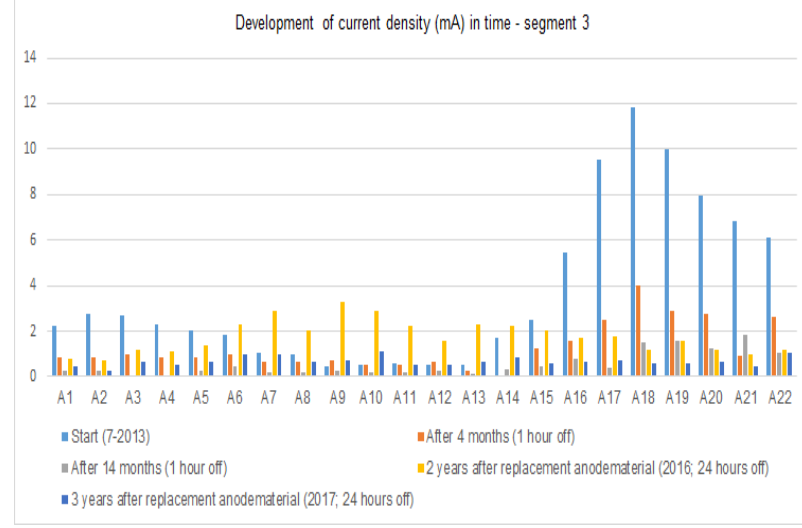

Fig. 14. Development of current output in time for segment 3.

During the first year the current output for the separate zinc foils (22 strips per segment) varied strongly in segment 3 (from 0.5 - $11.8 \mathrm{~mA} /$ strip; see Figure 14). The parts of segment 3 with patched areas (from zinc strip A5 to A16 and with the larger patched areas from A9 to A13; see Figures 15-16; [5]) showed much lower current outputs compared to the zinc strips in non-patched areas. The disbonded repair mortar caused a higher resistance and subsequent lower current densities at these locations.

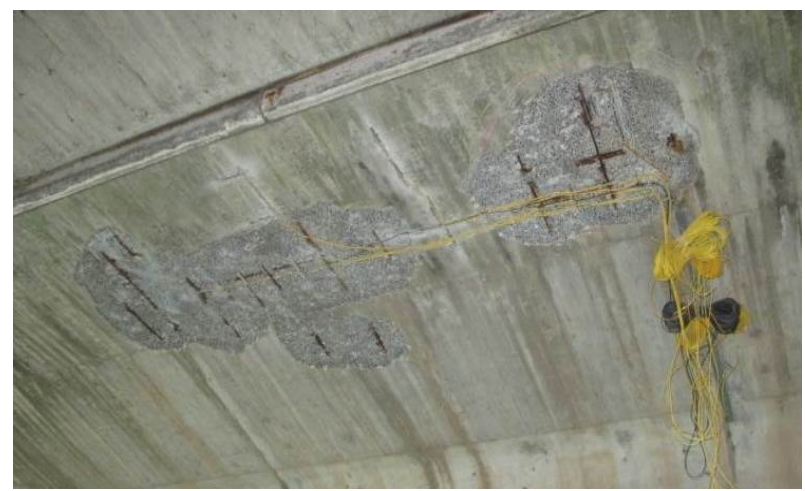

Fig. 15. Repair locations and RE's in segment 3.

As mentioned before the current output in segment 3 increased significantly after having the disbonded areas from the test phase repaired and the majority of the zinc anodes replaced in December 2014. At the same time the current distribution over the zinc strips became more equally spread (varying from $0.3-1.2 \mathrm{~mA} /$ strip in September $2017\left(\approx 0.28 \mathrm{~m}^{2}\right.$ for each strip); see Figure 14).

The zinc strips applied in segment 2, which has less patched areas, showed more equally distributed current outputs from the start: varying from $3.8-7.0 \mathrm{~mA} / \mathrm{strip}$ in July 2013 to $0.1-0.9 \mathrm{~mA} /$ strip in September 2017; see Figure 13).

To compare the current output of each zinc strip vs the potential reading of respective RE's is complicated due to the fact that the RE is affected by the current output of all neighboring zinc strips.

\subsection{Development of the concrete resistance in time}

The measurements of the concrete resistance were carried out by measuring the resistance between the rein- forcement and each individual RE and anode strip for each segment.

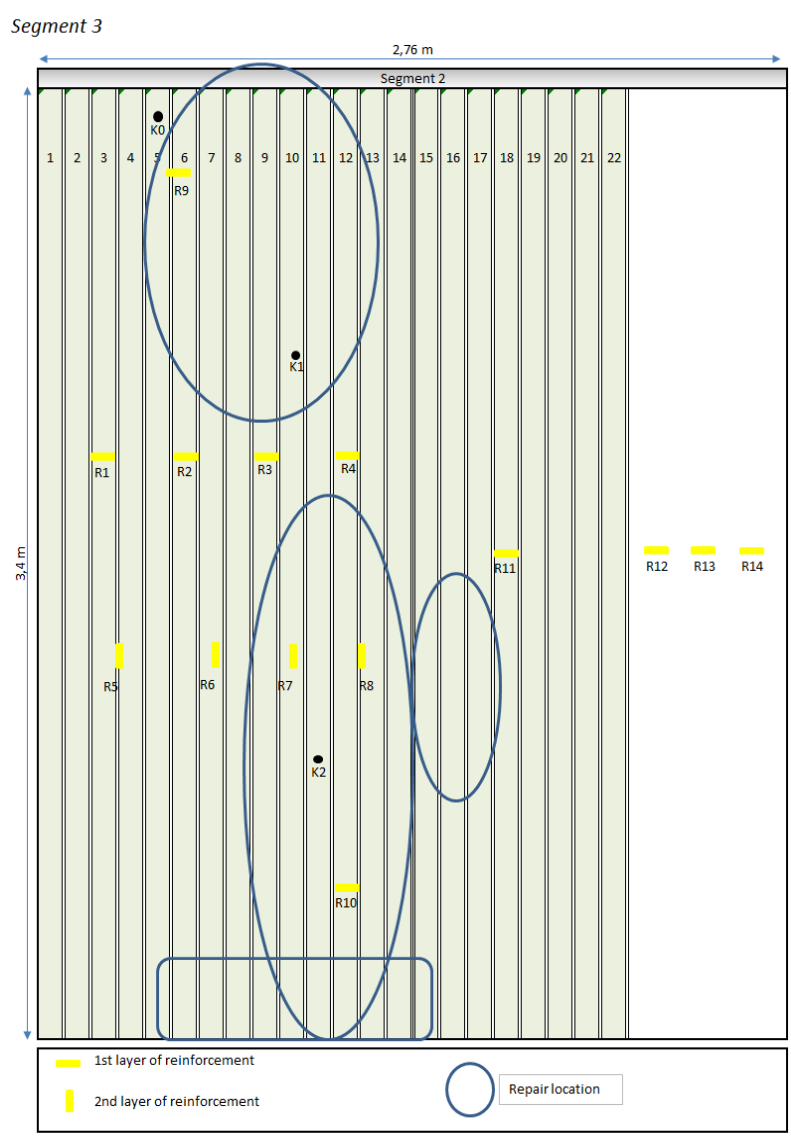

Fig. 16. Anode strips, RE's and repair locations in segment 3.

The measured values of the concrete resistance on these specific locations increased strongly over time (see Figure 17). At the start in 2013 the measured resistances at the RE's in segment 2 varied between 1 to $9 \mathrm{k} \Omega$ (with an average $(\mu)$ of $3.4 \mathrm{k} \Omega$ ), in segment 3 in the patched areas between 0.4 to $1 \mathrm{k} \Omega$ and between 1 to $6 \mathrm{k} \Omega$ in nonpatched areas $\left(\mu_{\text {total }}=2.2 \mathrm{k} \Omega\right)$. After 14 months $(2014)$, it increased substantially and the resistances varied at that moment from 7 to $212 \mathrm{k} \Omega$ in segment $2(\mu=45 \mathrm{k} \Omega)$ and in segment 3 from 2 to $5 \mathrm{k} \Omega$ in patched areas and from 4 to $130 \mathrm{k} \Omega$ in non-patched areas $\left(\mu_{\text {total }}=26 \mathrm{k} \Omega\right.$ ). The highest resistances in both segments were measured at RE's placed adjacent to the protected surface. Drying out of the (uncovered) concrete is considered to be the explanation for this observation.

During the next 3 years the measurements show a stabilized situation in segment 2. After 4 years the resistance at the RE's within the protected area (RE1 - RE9) show an average of $19 \mathrm{k} \Omega$ (compared to $18 \mathrm{k} \Omega$ in 2014 and $16 \mathrm{k} \Omega$ in 2016 in the same season of the year). In segment 3 the majority of the RE's was replaced in December 2014.

In 2013 the measured resistances at the anode strips in segment 2 varied between 57 to $217 \Omega(\mu=130 \Omega)$, in segment 3 in the (large) patched areas between 0.8 to 1.4 $\mathrm{k} \Omega$ and between 41 to $606 \Omega$ in non-patched areas $\left(\mu_{\text {total }}=\right.$ $432 \Omega$ ). After 14 months, these resistances were increased as well, varying at that moment from 135 to $678 \Omega$ in 
segment $2(\mu=253 \Omega)$ and in segment 3 from 1.2 to 3.1 $\mathrm{k} \Omega$ in patched areas and from 0.2 to $0.8 \mathrm{k} \Omega$ in non-patched areas $\left(\mu_{\text {total }}=1 \mathrm{k} \Omega\right)$. The highest resistances were measured at (partly) disbonded patch repairs in segment 3 .

\begin{tabular}{|c|c|c|c|c|c|c|}
\hline & \multicolumn{4}{|c|}{ Segment 2} & & \multirow{4}{*}{$\begin{array}{l}\text { increase of } \\
\text { resistance }\end{array}$} \\
\hline & $12-7-2013$ & $10-9-2014$ & \begin{tabular}{|l|}
$20-3-2015$ \\
\end{tabular} & $10-8-2016$ & $23-9-2017$ & \\
\hline & start & 14 months & 20 months & 3 years & 4 years & \\
\hline & \multicolumn{5}{|c|}{ Resistance } & \\
\hline \begin{tabular}{|l} 
RE's \\
\end{tabular} & $(\mathrm{k} \Omega)$ & $(\mathrm{k} \Omega)$ & $(\mathrm{k} \Omega)$ & $(\mathrm{k} \Omega)$ & $(\mathrm{k} \Omega)$ & $(\mathrm{k} \Omega)$ \\
\hline RE 1 & 1,96 & 14 & 23 & 14 & 17 & 15 \\
\hline RE 2 & 2,59 & 11 & 16 & 12 & 15 & 12 \\
\hline RE 3 & 1,86 & 10 & 17 & 10 & 12 & 10 \\
\hline RE 4 & 2,60 & 19 & 16 & 14 & 18 & 15 \\
\hline RE 5 & 2,06 & 15 & 26 & 13 & 14 & 12 \\
\hline RE 6 & 1,33 & 7 & 12 & 6 & 7 & 5 \\
\hline RE 7 & 2,33 & 19 & 16 & 11 & 13 & 11 \\
\hline RE 8 & 1,84 & 13 & 21 & 12 & 13 & 11 \\
\hline RE 9 & 5,43 & 56 & 84 & 52 & 64 & 59 \\
\hline RE 10 & 8,57 & 212 & 55 & 92 & 110 & 101 \\
\hline RE 11 & 3,08 & 48 & 33 & 28 & 34 & 31 \\
\hline \multirow[t]{2}{*}{ RE 12} & 6,83 & 116 & 90 & 74 & 94 & 87 \\
\hline & \multicolumn{5}{|c|}{ RE's vs Reinforcement } & \\
\hline average: & 3,4 & 45,0 & 34,1 & 28,2 & 34,2 & 31 \\
\hline \begin{tabular}{|l} 
Anode strips \\
\end{tabular} & $(\mathrm{k} \Omega)$ & $(\mathrm{k} \Omega)$ & & $(\mathrm{k} \Omega)$ & $(\mathrm{k} \Omega)$ & $(\mathrm{k} \Omega)$ \\
\hline A1 & 0,217 & 3,80 & & 0,383 & 3,5 & loose contact \\
\hline A2 & 0,112 & 0,135 & & 0,151 & 0,200 & 0,088 \\
\hline A3 & 0,129 & 0,154 & & 0,167 & 0,226 & 0,097 \\
\hline A4 & 0,136 & 0,170 & & 0,176 & 0,232 & 0,096 \\
\hline A5 & 0,137 & 0,182 & & 0,260 & 0,238 & 0,101 \\
\hline$A 6$ & 0,152 & 0,206 & & 0,190 & 0,242 & 0,090 \\
\hline A7 & 0,128 & 0,160 & & 0,153 & 0,196 & 0,068 \\
\hline A8 & 0,125 & 0,158 & & 0,157 & 0,205 & 0,080 \\
\hline A9 & 0,148 & 0,225 & & 0,420 & 1,5 & 1,4 \\
\hline A10 & 0,126 & 0,158 & & 0,143 & 0,184 & 0,058 \\
\hline A11 & 0,116 & 0,159 & & 0,146 & 0,188 & 0,072 \\
\hline A12 & 0,138 & 0,577 & & 0,518 & 0,700 & 0,562 \\
\hline A13 & 0,112 & 0,171 & & 0,583 & 1,4 & 1,3 \\
\hline A14 & 0,121 & 0,199 & & 0,200 & 0,533 & 0,412 \\
\hline A15 & 0,139 & 0,286 & & 0,169 & 2,4 & 2,3 \\
\hline A16 & 0,122 & 0,181 & & 0,205 & 0,225 & 0,103 \\
\hline A17 & 0,108 & 0,678 & & 0,263 & 0,246 & 0,138 \\
\hline A18 & 0,113 & 0,194 & & 0,196 & 0,475 & 0,362 \\
\hline A19 & 0,105 & 0,180 & & 0,164 & 0,208 & 0,103 \\
\hline A20 & 0,057 & 0,348 & & 0,443 & 0,266 & 0,209 \\
\hline A21 & 0,113 & 0,601 & & 45 & 29 & break in wiring \\
\hline \multirow[t]{2}{*}{ A22 } & 0,105 & 0,191 & & 0,238 & 1,5 & \begin{tabular}{|l|}
1,4 \\
\end{tabular} \\
\hline & \multicolumn{5}{|c|}{ Anode strips vs Reinforcement } & \\
\hline \begin{tabular}{|l|} 
average: $k \Omega$ \\
\end{tabular} & 0,13 & 0,25 & & 0,25 & 0,57 & 0,45 \\
\hline$A_{\text {stos }}-K_{s}$ & & & $12,2 \Omega$ & $47 \Omega$ & $16,7 \Omega$ & \\
\hline calculated: $\Omega$ & 5,4 & 9,7 & & 10,0 & 14,7 & $1 / R_{t}=\Sigma 1 / R_{n}$ \\
\hline
\end{tabular}

Fig. 17. Measured concrete resistances in segment 2.

Mainly in the last year (from 2016 to 2017) the resistances increased furthermore to an average of $568 \Omega$ in segment 2. Drying out of the concrete is considered to be the explanation for this observation. In segment 3 the measured resistances changed substantially after having the disbonded areas from the test phase repaired and the majority of the zinc anodes replaced in December 2014.

\subsection{Polarisation of the anode material}

The polarisation of the anode was measured in order to determine the condition of the anode material. Measurements were carried out 3 and 4 years after installation of the GCP system in segment 2 and after 3 years (with the new anode material) in segment 3 , by measuring the potential between the anode and each individual RE, as well as between each anode strip and the reinforcement.

The measured values show that the anode material is still in good condition after 3 and 4 years respectively (see Figures 18 and 19).

The measured potentials of the older anode strips in segment 3 (roughly anode strips A1-A3 and A18-A22) differ slightly from the anode material that was replaced in December 2014 (roughly A4-A17). At this moment the reason for this observation is uncertain, but could have been caused by the simultaneous replacement of the majority of the RE's in this segment in 2014. This will be investigated in the coming year.

\begin{tabular}{|c|c|c|c|c|c|c|c|}
\hline & & \multicolumn{6}{|c|}{ Segment 2} \\
\hline & & \multicolumn{6}{|l|}{ 10-8-2016 } \\
\hline & & \multicolumn{6}{|c|}{ measured anode potential after switching off CP system: RE (Ti $)$} \\
\hline & & on & $\begin{array}{c}\text { off after } 3 \\
\text { minutes }\end{array}$ & $\begin{array}{c}\text { off after } 30 \\
\text { minutes }\end{array}$ & $\begin{array}{c}\text { off after } 1 \\
\text { hour }\end{array}$ & $\begin{array}{c}\text { off after } 3 \\
\text { hours }\end{array}$ & \begin{tabular}{|c}
$\begin{array}{c}\text { polarisation } \\
\text { anode after } \\
3 \text { hours }\end{array}$ \\
\end{tabular} \\
\hline \multicolumn{2}{|c|}{ Segment 2} & $(-\mathrm{mV})$ & $(-\mathrm{mV})$ & $(-\mathrm{mV})$ & $(-\mathrm{mV})$ & $(-\mathrm{mV})$ & $(\mathrm{mV})$ \\
\hline RE 1 & Anode-M2 & 448 & 923 & 961 & 974 & 991 & 68 \\
\hline RE 2 & Anode-M2 & 431 & 906 & 937 & 947 & 958 & 52 \\
\hline RE 3 & Anode-M2 & 247 & 767 & 809 & 824 & 846 & 79 \\
\hline RE 4 & Anode-M2 & 249 & 774 & 817 & 831 & 850 & 76 \\
\hline RE 5 & Anode-M2 & 246 & 778 & 817 & 830 & 853 & 75 \\
\hline RE 6 & Anode-M2 & 263 & 784 & 822 & 836 & 858 & 74 \\
\hline RE 7 & Anode-M2 & 263 & 733 & 771 & 784 & 803 & 70 \\
\hline RE 8 & Anode - M2 & 311 & 787 & 822 & 832 & 849 & 62 \\
\hline RE 9 & Anode-M2 & 468 & 912 & 935 & 945 & 963 & 51 \\
\hline RE 10 & Anode-M2 & 212 & 763 & 811 & 830 & 864 & 101 \\
\hline RE 11 & Anode - M2 & 127 & 685 & 737 & 760 & 799 & 114 \\
\hline RE 12 & Anode-M2 & 79 & 637 & 691 & 716 & 763 & 126 \\
\hline $\operatorname{RE}\left(\mathrm{Ti}^{*}\right)$ & Zinc anode & & & & & & \\
\hline
\end{tabular}

Fig. 18. Anode polarisation in segment $2\left(\mathrm{vs} \mathrm{Ti}^{*}\right), 3$ years after installation.

\begin{tabular}{|c|c|c|c|c|c|c|c|}
\hline & & & Segment 2 & & & Segment & \\
\hline & & July 2013 & Septem & ber 2017 & July 2013 & Septen & ber 2017 \\
\hline & & $\begin{array}{c}\text { natural } \\
\text { potential }\end{array}$ & $\begin{array}{l}\text { measured } \\
\text { potential af } \\
\text { off CP sys }\end{array}$ & $\begin{array}{l}\text { anode strip } \\
\text { er switching } \\
\text { tem: steel }\end{array}$ & $\begin{array}{c}\text { natural } \\
\text { potential }\end{array}$ & $\begin{array}{l}\text { measurec } \\
\text { potential a } \\
\text { off } C P \text { sy }\end{array}$ & $\begin{array}{l}\text { anode strip } \\
\text { ter switching } \\
\text { tem: steel }\end{array}$ \\
\hline $\mid \begin{array}{l}\text { Anode } \\
\text { strip }\end{array}$ & \begin{tabular}{|}
$\begin{array}{l}\text { Reinfor- } \\
\text { cement }\end{array}$ \\
col
\end{tabular} & \begin{tabular}{|c|} 
before \\
starting up
\end{tabular} & $\begin{array}{c}\text { off after } 30 \\
\text { minutes }\end{array}$ & \begin{tabular}{|c|}
$\begin{array}{l}\text { off after } 24 \\
\text { hours }\end{array}$ \\
\end{tabular} & \begin{tabular}{|l} 
before \\
starting up
\end{tabular} & $\begin{array}{c}\text { off after } 30 \\
\text { minutes }\end{array}$ & $\begin{array}{c}\begin{array}{c}\text { off after } 24 \\
\text { hours }\end{array} \\
\end{array}$ \\
\hline & & & & & & $(-\mathrm{mV})$ & \\
\hline A1 & Steel & 1005 & 596 & 668 & 956 & & 697 \\
\hline A3 & Steel & 985 & 642 & $\begin{array}{l}776 \\
7757\end{array}$ & 920 & ${ }_{464}^{412}$ & $\begin{array}{l}517 \\
588\end{array}$ \\
\hline A4 & $\begin{array}{l}\text { Steel } \\
\text { Steel }\end{array}$ & $\begin{array}{l}960 \\
943\end{array}$ & $\begin{array}{l}676 \\
579\end{array}$ & $\begin{array}{l}751 \\
723\end{array}$ & $\begin{array}{l}927 \\
904\end{array}$ & $\begin{array}{l}464 \\
398\end{array}$ & $\begin{array}{l}588 \\
509\end{array}$ \\
\hline & Steel & 955 & 596 & 743 & 890 & 377 & 493 \\
\hline $\begin{array}{l}\text { A6 } \\
\text { A7 }\end{array}$ & $\begin{array}{l}\text { theel } \\
\text { Steel }\end{array}$ & 923 & 597 & $\begin{array}{l}740 \\
766\end{array}$ & 881 & $\begin{array}{l}407 \\
303\end{array}$ & 530 \\
\hline & $\begin{array}{l}\text { Steel } \\
\text { Steel }\end{array}$ & $\begin{array}{l}916 \\
937\end{array}$ & $\begin{array}{l}621 \\
615\end{array}$ & $\begin{array}{l}766 \\
757\end{array}$ & $\begin{array}{l}831 \\
752\end{array}$ & $\begin{array}{l}303 \\
180\end{array}$ & $\begin{array}{l}412 \\
262\end{array}$ \\
\hline A9 & Steel & 910 & 580 & 707 & 763 & 181 & 254 \\
\hline A10 & Steel & 909 & 595 & 739 & 769 & 107 & 144 \\
\hline $\begin{array}{l}\text { A11 } \\
\text { A12 }\end{array}$ & $\begin{array}{l}\text { Steel } \\
\text { Steel }\end{array}$ & $\begin{array}{l}918 \\
896\end{array}$ & $\begin{array}{l}584 \\
526\end{array}$ & $\begin{array}{l}725 \\
673\end{array}$ & $\begin{array}{l}744 \\
832\end{array}$ & $\begin{array}{l}176 \\
174\end{array}$ & $\begin{array}{l}232 \\
237 \\
227\end{array}$ \\
\hline $\mathrm{A} 13$ & $\begin{array}{l}\text { Steel } \\
\text { Steel }\end{array}$ & $\begin{array}{l}8900 \\
900\end{array}$ & $\begin{array}{l}526 \\
537\end{array}$ & 651 & $\begin{array}{l}696 \\
696\end{array}$ & 281 & 360 \\
\hline A14 & Steel & 916 & 615 & 758 & 781 & 284 & \\
\hline & & 895 & 608 & 74 & 843 & 219 & 298 \\
\hline A.16 & Steel & 904 & 636 & 784 & 774 & 351 & 458 \\
\hline & Steel & 922 & 629 & 777 & 805 & 346 & 458 \\
\hline 1018 & Steel & 904 & 616 & 740 & 838 & 449 & 570 \\
\hline 420 & ter & 年 & 647 & 773 & 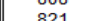 & 614 & $\begin{array}{ll}444 \\
775\end{array}$ \\
\hline A21 & Steel & 927 & break & & 880 & 421 & \\
\hline & & & & & 860 & & 740 \\
\hline
\end{tabular}

Fig. 19. Anode strip polarisation (vs steel) in segments 2 and 3 , 4 years and 3 years after installation respectively.

\section{Conclusions and recommendations}

\subsection{General}

Since 2013 potential decay values, current outputs and resistances were measured during a period of almost 5 years on 2 selected bridge segments in which a large amount of RE's were installed and on the surface narrow zinc strip anodes. These measurements showed interesting results on the effectiveness of the installed GCP system with surface-mounted zinc strip anodes (ZLA), on the development of the long term potential decay values and (protection) current outputs, and on the throwing power of galvanic anodes. The concrete resistance, being influenced by the moisture content of the concrete and the mortars used for repairs, was identified to have a major influence on the effectiveness of the installed GCP system and its development in time.

Monitoring of the installed CP system will continue and will be further reported in the future. 


\subsection{Effectiveness of the installed GCP system}

From startup the measurement results have demonstrated that the applied GCP system resulted in an effective solution. The depolarisation values complied with the code based protection criteria (ISO-EN12696; [3]) at almost all of the locations where RE's were installed.

The $2^{\text {nd }}$ reinforcement layer was protected as well (in non-patched areas), however with substantially less potential decay values compared to the $1^{\text {st }}$ layer.

The CP system was not only effective in the anode covered area but also more remote from this area, at least up to $20 \mathrm{~cm}$ adjacent to the zinc anodes during the first year after installation.

From the start the RE's located in patched areas showed less depolarisation compared to similar RE's in non-patched areas and in 2017 the code based criteria are not met at these locations. It is concluded and recommended that the effectiveness of a CP system should not be determined by RE's placed in (large) repairs.

\subsection{Potential decay values over time}

Depolarisation values gradually decreased over time (at the $1^{\text {st }}$ layer of reinforcement $48 \%$ in 4 years) and part of the installed RE's showed values after 4 years which did not comply with the code based protection criteria anymore, predominantly the readings from RE's installed at the depth of the $2^{\text {nd }}$ layer of reinforcement. Drying out of the concrete and polarisation of the steel are considered to be the explanation for this observation.

In December 2014, i.e. during the full scale project, some zinc strip anodes needed to be replaced because of the disbondment of repair mortar during the test phase. After replacing the zinc strips and repairing the disbonded areas, the system reacted immediately and showed good results again at all locations with installed RE's in this area. Moisturizing of the concrete and new installed anode material are considered to be the explanation for this observation. During the following 3 years the potential decay values decreased again (with $63 \%$ at the $1^{\text {st }}$ layer of reinforcement) due to drying out of the concrete.

The effectiveness of the GCP system to protect steel located at more distance from the protected area decreased over time as well (with approximately $50 \%$ in 4 years). After 2 years this positive side-effect due to the so called 'throwing power' was no longer measured with the RE's placed at a distance of $20 \mathrm{~cm}$ from the anode material. Drying out of the concrete is considered to be the explanation for this observation. It is concluded that the effectiveness of a GCP system adjacent to an area protected with surface-mounted zinc anodes, is limited in dense and/or dry concrete and declining in time. Therefor it is recommended not to overrate this side-effect if specific test results (mainly with regard to the concrete quality and the surface environment) on the effectiveness of the protection of steel reinforcement remote from anode material are not available.

\subsection{Current outputs over time}

The current outputs decreased strongly over time, with a strong accent in the first months. At the start in 2013 the total current output was $4-4.6 \mathrm{~mA} / \mathrm{m}^{2}$ anode (equal to roughly $6-8 \mathrm{~mA} / \mathrm{m}^{2}$ steel), which was reduced to 2.4 and $1.7 \mathrm{~mA} / \mathrm{m}^{2}$ anode in 2016 and 2017 respectively (equal to roughly 4 and $3 \mathrm{~mA} / \mathrm{m}^{2}$ steel). Drying out of the concrete and polarisation of the steel are considered to be the explanation for this observation.

In the first year current outputs at large patched areas were substantially lower compared to non-patched areas. This was mainly caused by the disbondment of (parts of) the repair mortar in the test phase. After repair of these areas the current output was more equally distributed over the anode material and variations in the current leveled with the concrete resistance at the subsequent zinc strips.

\section{References}

1. J. Gulikers, R. Giorgini, A.J. van den Hondel, Application of a surface-applied cathodic protection system on a light weight concrete bridge - Part I: Condition assessment, intervention options and trial investigations, Proceedings of Concrete Solutions Thessaloniki (2016)

2. A.J. van den Hondel, R. Giorgini, J. Gulikers, Application of a surface-applied cathodic protection system on a light weight concrete bridge - Part II: Developments in time of the effectiveness by potential decay values and current densities, Proceedings of Concrete Solutions - Thessaloniki (2016)

3. ISO-EN12696:2016, Cathodic protection of steel in concrete (Geneva, ISO (2016))

4. CUR Recommendation 45, Cathodic Protection of reinforcement in concrete constructions (in Dutch, Gouda, CUR (1996)).

5. A.J. van den Hondel, Execution of concrete repairs with the use of galvanic CP - Neerbosschebrug Nijmegen (in Dutch, Utrecht, RWS (2015)) 